\title{
The Metabolic Syndrome and Risk of Chronic Kidney Disease: Pathophysiology and Intervention Strategies
}

\author{
Heather A. LaGuardia, ${ }^{1}$ L. Lee Hamm, ${ }^{1}$ and Jing Chen ${ }^{2}$ \\ ${ }^{1}$ Tulane University, New Orleans, LA 70112, USA \\ ${ }^{2}$ Tulane School of Medicine, Tulane University 1430 Tulane Avenue, SL-45, New Orleans, LA 70112, USA \\ Correspondence should be addressed to Jing Chen, jchen@tulane.edu
}

Received 16 June 2011; Revised 14 December 2011; Accepted 14 December 2011

Academic Editor: Andréa Name Colado Simão

Copyright ( 92012 Heather A. LaGuardia et al. This is an open access article distributed under the Creative Commons Attribution License, which permits unrestricted use, distribution, and reproduction in any medium, provided the original work is properly cited.

\begin{abstract}
Metabolic syndrome is characterized by a clustering of cardiovascular risk factors, including abdominal obesity, elevated blood pressure and glucose concentrations, and dyslipidemia. The presence of this clinical entity is becoming more pervasive throughout the globe as the prevalence of obesity increases worldwide. Moreover, there is increased recognition of the complications and mortality related to this syndrome. This paper looks to examine the link between metabolic syndrome and the development of chronic kidney disease.
\end{abstract}

\section{Introduction}

Metabolic syndrome refers to a cluster of metabolic abnormalities (abdominal obesity, hyperglycemia, dyslipidemia, and hypertension) related to a state of insulin resistance, often associated with an overweight or obese state. This clinical entity has been known to increase the risk of cardiovascular disease (CVD), type 2 diabetes, chronic kidney disease (CKD), and total mortality.

Metabolic syndrome is highly prevalent worldwide, with a prevalence ranging from 10 to $40 \%$ in different populations [1-3]. Recently emerging data have suggested that metabolic syndrome is an important risk factor for CKD. CKD is a major risk factor for CVD and premature death [4-7]. Better understanding of the underlying pathophysiology of metabolic syndrome related to CKD will help to identify potential treatment strategies to reduce CKD risk. The purpose of this paper is to explore the potential pathophysiology and treatment strategies related to metabolic syndrome and CKD by integrating available data from the literature.

\section{Definition of Metabolic Syndrome}

In 1923, Kylin [8] first described a constellation of metabolic disturbances that included hypertension, hyperglycemia, and hyperuricemia. Later scientists noted that, when these syndromes clustered together, they could have disastrous health consequences and referred to the clustering as syndrome $\mathrm{X}$, insulin resistance syndrome, the deadly quartet, and obesity dyslipidemia syndrome [9-13]. Between 1998 and 2005, three definitions of metabolic syndrome had been developed and widely used (Table 1). The three definitions stated that the primary components of the syndrome included central obesity, dyslipidemia, elevated blood pressure, and increased glucose. Furthermore, previous studies have reported that all three definitions will identify persons at increased risk for diabetes, cardiovascular disease, and all-cause mortality [3, 14-16]. However, it is noteworthy that the NCEP ATP III definition was a more powerful predictor of CVD and diabetes than the IDF definition [17-20], while the IDF definition identified more patients than the NCEP ATP III definition $[19,21]$ according to recent studies. Therefore, NCEP ATP III definition may have had more clinical impact. In 2009, a global definition was developed by multiple organizations including the International Diabetes Federation (IDF), National Heart, Lung, and Blood Institute (NHLBI), the World Heart Federation, the International Atherosclerosis Society, and the American Heart Association (AHA) in an effort to harmonize clinical diagnosis of metabolic syndrome. Their definition, summarized in Table 2, is the 
TABLe 1

\begin{tabular}{|c|c|c|c|}
\hline Parameters & WHO (1998) & NCEP ATP3 (2001) & IDF (2005) \\
\hline Required & $\begin{array}{l}\text { Insulin resistance in the top } \\
25 \% \text {; glucose }\end{array}$ & & Waist $>94 \mathrm{~cm}$ (men) or $80 \mathrm{~cm}$ (women) \\
\hline Number of abnormalities & $>2$ & $>3$ & $>2$ \\
\hline Glucose & $\begin{array}{l}>6.1 \mathrm{mmol} / \mathrm{L}(110 \mathrm{mg} / \mathrm{dL}) \\
\text { 2-hour glucose } \\
>7.8 \mathrm{mmol} / \mathrm{L}(140 \mathrm{mg} / \mathrm{dL})\end{array}$ & $\begin{array}{l}>5.6 \mathrm{mmol} / \mathrm{L}(100 \mathrm{mg} / \mathrm{dL}) \\
\text { or drug treatment for } \\
\text { elevated blood glucose }\end{array}$ & $>5.6 \mathrm{mmol} / \mathrm{L}$ or diagnosed diabetes \\
\hline HDL cholesterol & $\begin{array}{l}<0.9 \mathrm{mmol} / \mathrm{L}(35 \mathrm{mg} / \mathrm{dL}) \\
(\mathrm{men}) ;<1.0 \mathrm{mmol} / \mathrm{L} \\
(40 \mathrm{mg} / \mathrm{dL})(\text { women })\end{array}$ & $\begin{array}{l}<1.0 \mathrm{mmol} / \mathrm{L} \text { men } \\
(40 \mathrm{mg} / \mathrm{dL})(\mathrm{men}) ; \\
<1.3 \mathrm{mmol} / \mathrm{L}(50 \mathrm{mg} / \mathrm{dL}) \\
\text { (women) or drug treatment } \\
\text { for low HDL-C }\end{array}$ & $\begin{array}{l}<1.0 \mathrm{mmol} / \mathrm{L}(40 \mathrm{mg} / \mathrm{dL})(\mathrm{men}) ;<1.3 \mathrm{mmol} / \mathrm{L} \\
(50 \mathrm{mg} / \mathrm{dL})(\text { women }) \text { or drug treatment for low } \\
\text { HDL-C }\end{array}$ \\
\hline Triglycerides & $\geq 1.7 \mathrm{mmol} / \mathrm{L}(150 \mathrm{mg} / \mathrm{dL})$ & $\begin{array}{l}\geq 1.7 \mathrm{mmol} / \mathrm{L}(150 \mathrm{mg} / \mathrm{dL}) \\
\text { or drug treatment for } \\
\text { elevated triglycerides }\end{array}$ & $\begin{array}{l}\geq 1.7 \mathrm{mmol} / \mathrm{L}(150 \mathrm{mg} / \mathrm{dL}) \text { or drug treatment for } \\
\text { elevated triglycerides }\end{array}$ \\
\hline Obesity & $\begin{array}{l}\text { Waist } / \text { hip ratio }>0.9 \text { (men) } \\
\text { or }>0.85 \text { (women) or BMI } \\
\geq 30 \mathrm{~kg} / \mathrm{m}^{2}\end{array}$ & $\begin{array}{l}\text { Waist } \geq 102 \mathrm{~cm}(\mathrm{men}) \text { or } \\
\geq 88 \mathrm{~cm} \text { (women) }\end{array}$ & Waist $\geq 94 \mathrm{~cm}$ (men) or $\geq 80 \mathrm{~cm}$ (women) \\
\hline Hypertension & $\geq 140 / 90 \mathrm{mmHg}$ & $\begin{array}{l}\geq 130 / 85 \mathrm{mmHg} \text { or drug } \\
\text { treatment for HTN }\end{array}$ & $\geq 130 / 85 \mathrm{mmHg}$ or drug treatment for HTN \\
\hline
\end{tabular}

TABLE 2

\begin{tabular}{lc}
\hline Measure & Categorical cut points \\
\hline Elevated waist circumference & Population- and country-specific definitions \\
Elevated triglycerides or drug treatment for elevated triglycerides & $\geq 150 \mathrm{mg} / \mathrm{dL}$ \\
Reduced HDL-C or drug treatment for reduced HDL-C & $<40 \mathrm{mg} / \mathrm{dL}$ in men, $<50 \mathrm{mg} / \mathrm{dL}$ in women \\
Elevated blood pressure or antihypertensive drug treatment & Systolic $\geq 130 \mathrm{mmHg}$ and/or diastolic $\geq 85 \mathrm{mmHg}$ \\
Elevated fasting glucose or drug treatment of elevated glucose & $\geq 100 \mathrm{mg} / \mathrm{dL}$ \\
\hline
\end{tabular}

Adapted from [22].

same as that by NCEP ATP III with an exception that the criteria for elevated waist circumference are based on population- and country- specific definitions [22].

\section{Metabolic Syndrome and Risk of Chronic Kidney Disease}

In the Last ten years, new research has examined the link between kidney disease and metabolic syndrome. In 2004, Chen et al. [23] showed that metabolic syndrome was an independent risk factor of CKD. They examined the association of metabolic syndrome and risk of CKD in over 6000 subjects who participated in the Third National Health and Nutrition Examination Survey (NHANES III) and documented that metabolic syndrome was independently associated with risk of CKD. In 2005, Kurella et al. [24] went further to include all metabolic syndrome traits in relation to risk for CKD. Using data from the ARIC study, a prospective longitudinal study of CV disease risk factors in 10,096 middle-aged nondiabetic adults, they found that over a nine-year time span metabolic syndrome increased the risk of developing chronic kidney disease by approximately $50 \%$.
The multivariable-adjusted odds ratio of developing CKD in those with metabolic syndrome was 1.43 (95\% CI 1.18-1.73). They also looked at the individual traits associated with the syndrome and found that compared with an adult who has no metabolic syndrome traits, risk for CKD in someone with all five of the traits is two and a half times higher. In 2006, Ninomiya et al. examined the relationship between metabolic syndrome and CKD [25]. They performed a slope analysis of the association between the glomerular filtration rate (GFR) slope and metabolic syndrome by using a multiple regression model. GFR decreased significantly faster in patients with 4 or more metabolic syndrome components compared with those who had 1 or no components. In 2007, Tozawa et al. [26] conducted a prospective study to examine metabolic syndrome as a risk factor for CKD in an Asian population. They examined CKD in 6,371 subjects without CKD or diabetes mellitus at baseline from 1997 through 2002 in Okinawa, Japan. During the 5-year followup, 369 (5.7\%) participants developed CKD. After adjusting for age, sex, current cigarette smoking, and alcohol drinking habits at baseline, the relative risk of developing CKD was 1.86 (95\% confidence interval: $1.43-2.41, P<0.0001)$ in subjects with metabolic syndrome. 


\section{Pathophysiology of Metabolic Syndrome which Predisposes to CKD}

4.1. Insulin Resistance. Insulin resistance has been considered an important pathophysiological factor for metabolic syndrome [27]. Insulin resistance has traditionally been defined by defective insulin action resulting in fasting hyperinsulinemia. Yet, even before fasting hyperinsulinemia develops, postprandial hyperinsulinemia exists. The resultant hyperinsulinemia stimulates glucose uptake by muscle and suppresses endogenous glucose production in the liver. In insulin-resistant conditions, the ability of insulin to augment glucose uptake and inhibit hepatic glucose production is impaired. This creates a state of hyperglycemia that stimulates beta cells to secrete large amounts of insulin postprandially. High insulin concentration may overstimulate the cells of the arterial wall in the skeletal muscle.

Binding of insulin to the insulin receptor normally leads to activation of its tyrosine kinase activity and autophosphorylation of specific tyrosine residues of the receptor. The activated insulin receptor phosphorylates tyrosine residues on substrate proteins initiating a signaling cascade. The two major pathways for insulin signaling are the phosphatidylinositol-3 kinase (PI-3K) and the mitogenactivated protein (MAP) kinase pathways [28]. The PI$3 \mathrm{~K}$ pathway is initiated by tyrosine phosphorylation of a member of the insulin receptor substrate family, which is associated with the p85 regulatory subunit leading to activation of the enzyme. PI-3K causes phosphatidylinositol 3,4,5-phosphate (PIP3) to be produced. This results in activation of Akt and downstream effector molecules that mediate metabolic response to insulin. This includes translocation of the glucose transporter type 4 (GLUT4) into the membrane. The MAP kinase pathway begins with phosphorylation of insulin receptor substrate, which binds Grb2 and activates Ras. Ras then binds and disinhibits Raf, which activates MEK1 kinase. MEK1 activates extracellular signal-regulated kinases ERK1 and ERK2. The ERKs mediate the mitogenic and proinflammatory responses of insulin signaling. In metabolic syndrome and type 2 diabetes, the pathways leading to activation of PI-3K are blocked, possibly through serine phosphorylation of the insulin receptor, leaving the MAP kinase pathway open. The activation of ERK MAPK pathway stimulates smooth muscle cell growth and proliferation, which maintains normal sensitivity to insulin even in insulin-resistant conditions. The overall effect may be to enhance atherogenesis.

Another key feature of metabolic syndrome is that free fatty acid production and release from adipocytes are not suppressed normally with the usual levels of insulin. Adipocyte resistance to the antilipolytic effect of insulin and the consequent elevated plasma free fatty acid levels may play an important role in the development of insulin resistance in muscle and other target tissues. Furthermore, excess fatty acid blocks the PI-3K signaling pathway. Impairment in the PI-3K pathway could contribute to vascular endothelial dysfunction due to decreased nitric oxide [27-29].

Kubo et al. examined the effect of hyperinsulinemia on renal function in a general Japanese population [30]. The study examined 2446 residents of a town in Japan age 4079 without renal failure and had them undergo a series of physical and laboratory analyses including glucose tolerance test. The results were interpreted through correlation analysis and showed serum insulin, blood pressure, total cholesterol, low-density lipoprotein cholesterol, triglycerides, and body mass index were all negatively correlated with the reciprocal of serum creatinine level. In multiple regression analysis, the correlation between the sum of insulin levels and the reciprocal of serum creatinine remained significant even after controlling for age, sex, body mass index, blood pressure, total cholesterol, high-density lipoprotein cholesterol, lowdensity lipoprotein cholesterol, triglycerides, alcohol intake, and smoking habits. This study suggested that hyperinsulinemia was a significant relevant factor of renal function in the general population. Renal dysfunction from insulin resistance and hyperglycemia is thought to be associated with the activation of the renin-angiotensin system (RAS) leading to elevated angiotensin II and aldosterone levels. The elevation affects the insulin/insulin-like growth factor1 signaling pathways, causing oxidative stress leading to endothelial disruption, and even the development of CVD [31]. Insulin resistance and hyperinsulinemia are associated with decreased endothelial production of nitric oxide and increased oxidative stress which have been also implicated in the progression of diabetic nephropathy [32].

4.2. Obesity and Waist Circumference. Visceral adipose tissue is the abdominal fat of the mesentery and omentum. When free fatty acids are released from the visceral fat, they drain into the portal circulation. It has been postulated that increases in this type of fat are directly associated with increases in risk for the sequel of metabolic syndrome [33]. In addition, increases in abdominal subcutaneous fat would release lipolysis products into the systemic circulation and avoid direct effects on hepatic metabolism (i.e., glucose production, lipid synthesis, and secretion of prothrombotic proteins such as fibrinogen and plasminogen activator inhibitor 1) [34]. Furthermore, human adipocytes produce an as yet unidentified mineralocorticoid-releasing factor that stimulates adrenal aldosterone production by means of paracrine or endocrine mechanisms [35, 36]. Elevated levels of aldosterone promote insulin resistance and hypertension and therefore the development of the metabolic syndrome [37].

When biopsies of obese patients are examined, focal and segmental glomerulosclerosis and glomerulomegaly are the most common morphological renal lesions [38]. Early changes noted upon review of biopsies seen in nondiabetic patients with only mild metabolic abnormalities and mild hypertension include increased glomerular cell proliferation, increased mesangial matrix, thicker basement membrane, and increased expression of glomerular transforming growth factor-beta [39]. The mechanisms of obesity-induced renal injury likely result from a combination of hemodynamic and metabolic abnormalities. Many factors contribute to the increase in both glomerular filtration rate (GFR) and rise in renal plasma flow (RPF) observed in obese patients. 
Insulin resistance likely causes an increase in the efferent arteriolar pressure due to decrease of noradrenalineinduced efferent arteriolar constriction by insulin. Therefore, the transcapillary pressure gradient increases resulting in hyperfiltration [40]. Insulin also stimulates the synthesis of IGF-1 and IGF-2, both promoting glomerular hypertrophy [38]. In 2011, Mathew et al. proposed that circulating cytokines (leptin, adiponectin) and inflammatory markers produced by adipose tissue are directly affecting cells in the renal glomeruli [28]. Moreover, elevated aldosterone in obesity promotes fibrosis and target-organ dysfunction by stimulating plasminogen activator inhibitor, transforming growth factor $\beta 1$, and reactive oxygen species (ROS) [4143 ]. Aldosterone also promotes loss of glomerular podocytes and a consequent decrease in the slit-pore membrane integrity, with consequent proteinuria [44-47]. In addition, aldosterone increases renal tubular and interstitial oxidative stress and inflammation, processes that promote salt-induced tubuloglomerular injury, by means of rapid nongenomic effects [28].

4.3. Dyslipidemia. This condition is characterized by an increase in elevated triglycerides (and increased VLDL particle number), increased small LDL particles, and low HDL cholesterol. Increased numbers of VLDL and LDL particles lead to an increased level of total apo-B usually observed with atherogenic dyslipidemia. Additionally, small triglyceride-rich lipoproteins have also been found to be atherogenic [48]. The LDL particles associated with the metabolic syndrome and atherogenic dyslipidemia tend to be small and dense. Smaller LDLs have been postulated to penetrate more easily into the arterial wall as well as be more prone to atherogenic modification [49]. Low HDL is a risk predictor for the atherogenic process.

Dyslipidemia seen in metabolic syndrome is postulated to cause CKD by inflammation and increased oxidative stress, which would cause endothelial damage and atherosclerosis diseases [50-52]. Manttari et al. used metaanalysis to postulate that elevated triglycerides and low HDL cholesterol in the plasma are independent risk factors for the development of chronic kidney disease [53]. Additionally, Muntner et al. [54] noted in the ARIC study that high triglycerides and low HDL cholesterol in plasma significantly increased the probability of developing renal dysfunction. It has even been examined that use of statins may slow the progression of chronic kidney disease [55].

4.4. Elevated Blood Pressure. Obese persons have a higher prevalence of elevated blood pressure than lean persons. Moreover, a higher blood pressure is a strong risk factor for cardiovascular disease [56]. Well-known complications of hypertension are $\mathrm{CHD}$, stroke, left ventricular hypertrophy, heart failure, and chronic renal failure. The relation between insulin resistance and hypertension is well established [57]. Insulin is a vasodilator when given intravenously to people who are not obese [58]. In the setting of insulin resistance, the vasodilatory effect of insulin can be lost [59], but the renal effect on sodium reabsorption preserved. Metabolic syndrome is also implicated in salt-sensitive hypertension.
The enhanced insulin resistance in CKD may increase sodium reabsorption by hyperinsulinemia. This results in sodium retention and salt-sensitive hypertension. In addition, Fujita [60] noted that, in obese rats, adipocyte-derived aldosterone releasing factors lead to hyperaldosteronism. Hyperaldosteronism results in salt-sensitive hypertension as well as proteinuria in the obese hypertensive rats. Salt loading exacerbated the proteinuria and also resulted in cardiac diastolic dysfunction. Fujita proposed that salt and aldosterone worked in synergy with the cardiovascular system through overproduction of oxidative stress. ROS, induced by adipokines such as tumor necrosis factor-alpha, nonesterified fatty acids, angiotensinogen activated the mineralocorticoid receptor, in an aldosterone-independent fashion. The hypothesis proposed aldosterone and mineralocorticoid receptor activation may play an important role in the development of salt-sensitive hypertension, as well as the cardiovascular and renal injury seen in metabolic syndrome. Fatty acids themselves can mediate relative vasoconstriction [61].

\section{Interventions}

5.1. Diet. Some experts debate the clinical utility of aggregating individual risk factors into a specific diagnosis of metabolic syndrome when medically each risk factor is addressed separately. At this time, there is no single metabolic syndrome diet recommended. The main strategy has been to reverse contributory factors such as an atherogenic diet, obesity, and a sedentary lifestyle [62]. Weight management and physical activity are recommended as first-line therapy in order to delay the progression of symptoms [63]. Epidemiological evidence suggests a lower prevalence of metabolic syndrome with dietary patterns that are rich in fruits, vegetables, whole grains, dairy products, and unsaturated fats. Research from the dietary approaches to stop hypertension (DASH) intervention studies demonstrates beneficial effects of an eating plan rich in low-fat dairy foods, fruits, and vegetables on blood pressure and lipids. A reduced calorie DASH diet compared to a control and weight loss diet reduced most of the metabolic syndrome risks in both men and women and improved some components beyond that seen in a weight loss diet [64]. The DASH diet which is rich in calcium, magnesium, and potassium may also lower the risk of stroke and hypertension. Fiber and other phytonutrients in fruit and vegetables may be protective by lowering cholesterol or markers of inflammation. Some studies $[65,66]$ suggest an inverse association between dairy consumption and risk for metabolic syndrome. In young overweight adults, the incidence of metabolic syndrome were lower by more than two-thirds among individuals in the highest category of dairy intake ( $>5$ servings per day) compared to lowest category $(<1.5$ servings a day) [67]. In addition, a dietary pattern that had higher intake of low-fat dairy has been associated with a lower risk of type 2 diabetes in middle aged or older women and with a $9 \%$ lower risk for type 2 diabetes in men [65]. Giugliano et al. explored possible mechanisms underlying a dietary intervention and randomly assigned 180 patients (99 men and 81 women) with the metabolic syndrome to either 
a Mediterranean-style diet (an increase in daily consumption of whole grains, vegetables, fruit, nuts, and olive oil) or a cardiac diet with a decreased fat intake composed of less than thirty percent of total calories. Only forty patients in the intervention group still had metabolic syndrome after two years compared with seventy-eight patients who consumed the control diet [68].

Given the increased blood pressure reactivity to dietary salt in patients with metabolic syndrome, a reduction in dietary salt may have a beneficial effect on lowering systolic blood pressure as suggested by Hoffman's study ( $8.2 \mathrm{~g} /$ day to $2.3 \mathrm{~g} /$ day of salt) [69]. Recently, Chen et al. reported that metabolic syndrome may enhance blood pressure response to sodium intake in nondiabetics [70]. However, if lowsodium diet could lead reduction of metabolic syndromerelated morbidity and mortality remains to be investigated in clinical trials.

5.2. Oral Hypoglycemic Agents. In the Diabetes Prevention Program trial, metformin reduced the risk of diabetes and the metabolic syndrome in individuals with impaired fasting glucose and impaired glucose tolerance [71]. The study examined 3234 nondiabetic persons with elevated fasting and postload plasma glucose concentrations. Then assigned participants to metformin ( $850 \mathrm{mg}$ twice daily) or a lifestylemodification program and followed them for 2.8 years. The lifestyle intervention reduced the incidence by $58 \%(95 \%$ CI, 48\%-66\%) and metformin by $31 \%$ (95\% C, 17\%-43\%), as compared with placebo; the lifestyle intervention was significantly more effective than metformin. In a 10-year followup of this study, it was found that prevention or delay of diabetes with lifestyle intervention or metformin could persist for at least 10 years [72]. In patients with the metabolic syndrome but normal glucose tolerance, metformin has been shown to improve endothelial function [73]. Unfortunately, metformin is contraindicated in patients with chronic kidney disease with reduced GFR. This is due to the fact that renal clearance of metformin and lactate is reduced, leading to increased levels of both and possibly causing lactic acidosis due to a buildup of lactic acid [74].

Thiazolidinediones have also been associated with protection effects. In the DREAM study, rosiglitazone reduced the three-year incidence of type 2 diabetes by 60 percent in patients with impaired glucose tolerance or impaired fasting glucose who were taking the medication at the time of testing [75]. The management of insulin resistance with thiazolidinediones (TZDs) has resulted in greater attention to activators of the peroxisome proliferator-activated receptors (PPARs). TZDs exert much of their effect on insulin resistance via activation of PPAR-gamma. TZDs not only improve glucose control but favorably affect both free fatty acid metabolism and insulin action. Szapary et al. examined the effect of pioglitazone in patients with the metabolic syndrome and demonstrated a significant increase in HDL$\mathrm{C}$ and favorable effects on lipid subfractions without an effect on triglycerides or low-density lipoprotein cholesterol (LDL-C) concentrations [76]. Tan et al. [77] noted that pioglitazone therapy resulted in greater improvements in the atherogenic index of plasma and lowered triglyceride levels effectively while achieving greater increases in HDL-C when compared with rosiglitazone.

5.3. Lipid-Lowering Agents. The efficacy of statins in making marked reductions in LDL cholesterol, modest reductions in TG, and small increases in HDL cholesterol is well documented. ATP III recommended a goal serum LDL cholesterol of less than $100 \mathrm{mg} / \mathrm{dL}(2.6 \mathrm{mmol} / \mathrm{L})$ for $\mathrm{sec}-$ ondary prevention in patients with type 2 diabetes [78, 79]. For this reason the use in patient with metabolic syndrome has been examined. Patients in the $4 \mathrm{~S}$ trial who met the lipid criteria for the metabolic syndrome were treated with simvastatin, 20 or $40 \mathrm{mg} / \mathrm{d}$. It was noted that they had a $37.5 \%$ versus a $36.0 \%$ decrease, respectively, in LDL cholesterol, a $24.1 \%$ versus $6.7 \%$ decrease in TG, and a $10.3 \%$ versus a $0.6 \%$ increase in HDL cholesterol [80]. Rosuvastatin, $10 \mathrm{mg} / \mathrm{d}$ administered to patients with the metabolic syndrome, reduced LDL cholesterol by $47 \%$, apolipoprotein B by $37 \%$, and TG by $23 \%$, while increasing HDL cholesterol by $10 \%$ [81]. Multiple statins have been shown to reduce cardiovascular events in patients with and without CVD, suggesting that this is a class effect of these drugs. Some of the CVD risk reduction produced by statins may be attributable to nonlipid pleiotrophic effects of these drugs [82]. Treatment of patients with known coronary disease and the metabolic syndrome with atorvastatin $80 \mathrm{mg}$, compared to atorvastatin $10 \mathrm{mg}$, decreased the rate of major cardiovascular events at five years (9.5 versus 13 percent, HR 0.71, 95\% CI 0.61-0.84) [79].

In 2009, Robinson et al. [83] evaluated the lipid-lowering efficacy of ezetimibe/simvastatin $10 / 20 \mathrm{mg}$ versus atorvastatin 10 or $20 \mathrm{mg}$, and ezetimibe/simvastatin $10 / 40 \mathrm{mg}$ versus atorvastatin $40 \mathrm{mg}$ in 1,128 patients with hypercholesterolemia and the metabolic syndrome. They noted that greater improvements in the levels of LDL cholesterol, nonhigh-density lipoprotein cholesterol, apolipoprotein B, and lipid/lipoprotein ratios resulted with ezetimibe/simvastatin compared with atorvastatin at all specified dose comparisons $(P<0.001)$.

5.4. Antihypertensive Therapy. Patients with hypertension and the metabolic syndrome have high risk of suffering from future cardiovascular and kidney disease. At present there are no large-scale, randomized trials to establish the antihypertensive drug of choice for patients with metabolic syndrome. Most investigators have considered angiotensinconverting enzyme inhibitors (ACEI) as superior to betablockers and thiazide diuretics [84]. The adverse potential metabolic side effects of thiazides and beta-blockers on increase of blood lipids and glucose have led to favoring of ACEI and calcium channel blockers (CCB) [85]. Betablockers also promote weight gain, and both thiazides and beta-blockers are associated with an increased incidence of diabetes, compared to CCB and ACEI [86].

Wright et al. [87] conducted subgroup analysis of the ALLHAT study reporting that findings fail to support the preference for CCBs, alpha-blockers, or ACEIs compared with thiazide-type diuretics in patients with the metabolic 
syndrome. Wright examined the metabolic and cardiovascular outcomes of the ALLHAT trial in patients stratified according to race (black versus nonblack) and the presence or absence of the metabolic syndrome. Among all the patients studied, chlorthalidone had the least favorable effects on blood glucose and cholesterol levels than lisinopril, amlodipine. In patients without the metabolic syndrome, both the ACEI and the CCB lowered the incidence of type 2 diabetes significantly, compared to the thiazide [88]. Wright also noted that black patients with the metabolic syndrome had worse outcomes with lisinopril, compared to chlorthalidone, with respect to every outcome measured, likely resulting from a $3-5 \mathrm{mmHg}$ higher systolic pressure in the black patients on lisinopril, compared to those on chlorthalidone. Wright concluded that ACEI should not be the first-line monotherapy for black patients with the metabolic syndrome [87].

5.5. Resistance Training. Over the last decade, physicians have been examining the effects of resistance training on metabolic syndrome. Reduced muscle mass as a result of normal aging and decreased physical activity have been postulated behind the high prevalence of this disorder. Improved glycemic control, improved blood lipid profiles, and decreased BP are important for reducing microvascular and macrovascular complications in people with metabolic risk. As with increasing adiposity in aging and loss of muscle mass, the insulin-mediated glucose uptake and TG disposal in the skeletal muscle of elderly persons is reduced and the maintenance of a large muscle mass can contribute to the prevention of type 2 diabetes, which is associated with cardiovascular disease. Resistance training is contributing to the decrease of major risk factors for the metabolic syndrome and should be recommended for the management of type 2 diabetes. Although the number of studies on the effects of resistance training on blood pressure is small, Strasser conducted meta-analysis confirming that resistance training does not increase blood pressure as was once thought and may even have potential benefits on resting systolic blood pressure [89].

5.6. Surgery. In the prospective controlled clinical study conducted by Lee et al., metabolic syndrome was prevalent in $52.2 \%$ of morbidly obese individual enrolled. Significant weight reduction 1 year after surgery markedly improved all aspects of the metabolic syndrome and resulted in a cure rate of $95.6 \%$ [90]. Obesity surgery performed by laparoscopic surgery is recommended for obese patients with the metabolic syndrome that have not responded to conservative measures.

\section{Conclusion}

Compelling data have indicated that metabolic syndrome increases the risk of CKD. Experimental studies have suggested that metabolic syndrome may induce CKD via multiple mechanic pathways. While we are waiting for randomized clinical trial and even new drug development in treating metabolic syndrome to reduce risk of CKD, current key strategies should include prevention and treatment of obesity and insulin resistance. Lifestyle modification particularly including low sodium diet and increasing physical activity would be important approaches. Aldosterone antagonists would also be particular of interest to test in clinical trial in treating metabolic syndrome to reduce CKD risk. At the present, early identification of metabolic syndrome and treatment of individual components of metabolic syndrome may reduce the risk of CKD. However, these approaches need be further tested in large randomized clinical trial to verify their effect on reducing CKD risk.

\section{References}

[1] R. H. Eckel, K. G. M. M. Alberti, S. M. Grundy, and P. Z. Zimmet, "The metabolic syndrome," The Lancet, vol. 375, no. 9710, pp. 181-183, 2010.

[2] D. Gu, K. Reynolds, X. Wu et al., "Prevalence of the metabolic syndrome and overweight among adults in China," The Lancet, vol. 365, no. 9468, pp. 1398-1405, 2005.

[3] E. S. Ford, "Prevalence of the metabolic syndrome defined by the international diabetes federation among adults in the U.S," Diabetes Care, vol. 28, no. 11, pp. 2745-2749, 2005.

[4] J. Coresh, E. Selvin, L. A. Stevens et al., "Prevalence of chronic kidney disease in the United States," Journal of the American Medical Association, vol. 298, no. 17, pp. 2038-2047, 2007.

[5] A. M. El Nahas and A. K. Bello, "Chronic kidney disease: the global challenge," The Lancet, vol. 365, no. 9456, pp. 331-340, 2005.

[6] P. Muntner, J. He, L. Hamm, C. Loria, and P. K. Whelton, "Renal insufficiency and subsequent death resulting from cardiovascular disease in the United States," Journal of the American Society of Nephrology, vol. 13, no. 3, pp. 745-753, 2002.

[7] A. S. Go, G. M. Chertow, D. Fan, C. E. McCulloch, and C. Y. Hsu, "Chronic kidney disease and the risks of death, cardiovascular events, and hospitalization," The New England Journal of Medicine, vol. 351, no. 13, pp. 1296-1305, 2004.

[8] E. Kylin, "Hypertension-hyperglycemia-hyperuricemia syndrome," Zentralblatt fur InnereMedizin, p. 44, 1923.

[9] J. Vague, "La diffférenciacion sexuelle, facteur déterminant des formes de l'obésité," La Presse Médicale, vol. 30, pp. 339-340, 1947.

[10] H. Haller, "Epidermiology and associated risk factors of hyperlipoproteinemia," Zeitschrift fur die Gesamte Innere Medizin und Ihre Grenzgebiete, vol. 32, no. 8, pp. 124-128, 1977.

[11] P. Singer, "Diagnosis of primary hyperlipoproteinemias," Zeitschrift fur die Gesamte Innere Medizin und Ihre Grenzgebiete, vol. 32, no. 9, pp. 129-133, 1977.

[12] G. B. Phillips, "Sex hormones, risk factors and cardiovascular disease," The American Journal of Medicine, vol. 65, no. 1, pp. 7-11, 1978.

[13] G. M. Reaven, "Role of insulin resistance in human disease," Diabetes, vol. 37, no. 12, pp. 1595-1607, 1988.

[14] H. M. Lakka, D. E. Laaksonen, T. A. Lakka et al., "The metabolic syndrome and total and cardiovascular disease mortality in middle-aged men," Journal of the American Medical Association, vol. 288, no. 21, pp. 2709-2716, 2002.

[15] D. E. Laaksonen, H. M. Lakka, L. K. Niskanen, G. A. Kaplan, J. T. Salonen, and T. A. Lakka, "Metabolic syndrome and 
development of diabetes mellitus: application and validation of recently suggested definitions of the metabolic syndrome in a prospective cohort study," American Journal of Epidemiology, vol. 156, no. 11, pp. 1070-1077, 2002.

[16] E. S. Ford and W. H. Giles, "A comparison of the prevalence of the metabolic syndrome using two proposed definitions," Diabetes Care, vol. 26, no. 3, pp. 575-581, 2003.

[17] E. Mannucci, M. Monami, B. Cresci et al., "National cholesterol education program and international diabetes federation definitions of metabolic syndrome in the prediction of diabetes: results from the firenze-bagno a ripoli study," Diabetes, Obesity and Metabolism, vol. 10, no. 5, pp. 430-435, 2008.

[18] P. M. Nilsson, G. Engström, and B. Hedblad, "The metabolic syndrome and incidence of cardiovascular disease in nondiabetic subjects - a population-based study comparing three different definitions," Diabetic Medicine, vol. 24, no. 5, pp. 464-472, 2007.

[19] K. M. Choi, S. M. Kim, Y. E. Kim, D. S. Choi, S. H. Baik, and J. Lee, "International diabetes federation: prevalence and cardiovascular disease risk of the metabolic syndrome using National Cholesterol Education Program and International Diabetes Federation definitions in the Korean population," Metabolism: Clinical and Experimental, vol. 56, no. 4, pp. 552558, 2007.

[20] P. C. Y. Tong, A. P. Kong, W. Y. So et al., "The usefulness of the International Diabetes Federation and the National Cholesterol Education Program's Adult Treatment Panel III definitions of the metabolic syndrome in predicting coronary heart disease in subjects with type 2 diabetes," Diabetes Care, vol. 30, no. 5, pp. 1206-1211, 2007.

[21] V. G. Athyros, E. S. Ganotakis, M. Elisaf, and D. P. Mikhailidis, "The prevalence of the metabolic syndrome using the National Cholesterol Educational Program and International Diabetes Federation definitions," Current Medical Research and Opinion, vol. 21, no. 8, article 3094, pp. 1157-1159, 2005.

[22] K. G. M. M. Alberti, R. H. Eckel, S. M. Grundy et al., "Harmonizing the metabolic syndrome: a joint interim statement of the International Diabetes Federation Task Force on Epidemiology and Prevention; National Heart, Lung, and Blood Institute; American Heart Association; World Heart Federation; International Atherosclerosis Society; and International Association for the Study of Obesity," Circulation, vol. 120, no. 16, pp. 1640-1645, 2009.

[23] J. Chen, P. Muntner, L. L. Hamm et al., "The metabolic syndrome and chronic kidney disease in U.S. adults," Annals of Internal Medicine, vol. 140, no. 3, pp. 167-I39, 2004.

[24] M. Kurella, J. C. Lo, and G. M. Chertow, "Metabolic syndrome and the risk for chronic kidney disease among nondiabetic adults," Journal of the American Society of Nephrology, vol. 16, no. 7, pp. 2134-2140, 2005.

[25] T. Ninomiya, Y. Kiyohara, M. Kubo et al., "Metabolic syndrome and CKD in a general Japanese population: the hisayama study," American Journal of Kidney Diseases, vol. 48, no. 3, pp. 383-391, 2006.

[26] M. Tozawa, C. Iseki, K. Tokashiki et al., "Metabolic syndrome and risk of developing chronic kidney disease in Japanese adults," Hypertension Research, vol. 30, no. 10, pp. 937-943, 2007.

[27] A. Natali and E. Ferrannini, "Hypertension, insulin resistance, and the metabolic syndrome," Endocrinology and Metabolism Clinics of North America, vol. 33, no. 2, pp. 417-429, 2004.
[28] A. V. Mathew, S. Okada, and K. Sharma, "Obesity related kidney disease," Current Diabetes Reviews, vol. 7, no. 1, pp. 4149, 2011.

[29] D. Le Roith and Y. Zick, "Recent advances in our understanding of insulin action and insulin resistance," Diabetes Care, vol. 24, no. 3, pp. 588-597, 2001.

[30] M. Kubo, Y. Kiyohara, I. Kato et al., "Effect of hyperinsulinemia on renal function in a general Japanese population: the Hisayama study," Kidney International, vol. 55, no. 6, pp. 24502456, 1999.

[31] C. Manrique, G. Lastra, M. Gardner, and J. R. Sowers, "The renin angiotensin aldosterone system in hypertension: roles of insulin resistance and oxidative stress," Medical Clinics of North America, vol. 93, no. 3, pp. 569-582, 2009.

[32] P. A. Sarafidis and L. M. Ruilope, "Insulin resistance, hyperinsulinemia, and renal injury: mechanisms and implications," American Journal of Nephrology, vol. 26, no. 3, pp. 232-244, 2006.

[33] O. Bosello and M. Zamboni, "Visceral obesity and metabolic syndrome," Obesity Reviews, vol. 1, no. 1, pp. 47-56, 2000.

[34] H. Aubert, C. Frère, M. F. Aillaud, P. E. Morange, I. JuhanVague, and M. C. Alessi, "Weak and non-independent association between plasma TAFI antigen levels and the insulin resistance syndrome," Journal of Thrombosis and Haemostasis, vol. 1, no. 4, pp. 791-797, 2003.

[35] V. Lamounier-Zepter and M. Ehrhart-Bornstein, "Fat tissue metabolism and adrenal steroid secretion," Current Hypertension Reports, vol. 8, no. 1, pp. 30-34, 2006.

[36] T. L. Goodfriend, D. L. Ball, B. M. Egan, W. B. Campbell, and K. Nithipatikom, "Epoxy-Keto derivative of Linoleic acid stimulates aldosterone secretion," Hypertension, vol. 43, no. 2, pp. 358-363, 2004.

[37] J. R. Sowers, A. Whaley-Connell, and M. Epstein, "Narrative review: the emerging clinical implications of the role of aldosterone in the metabolic syndrome and resistant hypertension," Annals of Internal Medicine, vol. 150, no. 11, pp. 776-783, 2009.

[38] N. Kambham, G. S. Markowitz, A. M. Valeri, J. Lin, and V. D. D'Agati, “Obesity-related glomerulopathy: an emerging epidemic," Kidney International, vol. 59, no. 4, pp. 1498-1509, 2001.

[39] J. R. Henegar, S. A. Bigler, L. K. Henegar, S. C. Tyagi, and J. E. Hall, "Functional and structural changes in the kidney in the early stages of obesity," Journal of the American Society of Nephrology, vol. 12, no. 6, pp. 1211-1217, 2001.

[40] D. K. Papafragkaki and G. Tolis, "Obesity and renal disease: a possible role of leptin," Hormones, vol. 4, no. 2, pp. 90-95, 2005.

[41] J. R. Sowers, "Metabolic risk factors and renal disease," Kidney International, vol. 71, no. 8, pp. 719-720, 2007.

[42] S. A. Cooper, A. Whaley-Connell, J. Habibi et al., "Reninangiotensin-aldosterone system and oxidative stress in cardiovascular insulin resistance," American Journal of Physiology, vol. 293, no. 4, pp. H2009-H2023, 2007.

[43] M. Epstein, "Aldosterone blockade: an emerging strategy for abrogating progressive renal disease," The American Journal of Medicine, vol. 119, no. 11, pp. 912-919, 2006.

[44] M. Nagase, S. Yoshida, S. Shibata et al., "Enhanced aldosterone signaling in the early nephropathy of rats with metabolic syndrome: possible contribution of fat-derived factors," Journal of the American Society of Nephrology, vol. 17, no. 12, pp. 34383446, 2006. 
[45] J. R. Sowers, "Hypertension, angiotensin II, and oxidative stress," The New England Journal of Medicine, vol. 346, no. 25, pp. 1999-2001, 2002.

[46] A. S. Bomback and P. J. Klemmer, "Renal injury in extreme obesity: the important role of aldosterone," Kidney International, vol. 74, no. 9, p. 1216, 2008.

[47] A. Whaley-Connell, J. Habibi, Y. Wei et al., "Mineralocorticoid receptor antagonism attenuates glomerular filtration barrier remodeling in the transgenic Ren2 rat," American Journal of Physiology, vol. 296, no. 5, pp. F1013-F1022, 2009.

[48] R. M. Krauss, "Atherogenicity of triglyceride-rich lipoproteins," American Journal of Cardiology, vol. 81, no. 4, pp. 13B17B, 1998.

[49] R. M. Krauss, "Dense low density lipoproteins and coronary artery disease," American Journal of Cardiology, vol. 75, no. 6, pp. 53B-57B, 1995.

[50] H. C. Ou, W. J. Lee, S. D. Lee et al., "Ellagic acid protects endothelial cells from oxidized low-density lipoproteininduced apoptosis by modulating the PI3K/Akt/eNOS pathway," Toxicology and Applied Pharmacology, vol. 248, no. 2, pp. 134-143, 2010.

[51] H. C. Ou, F. P. Chou, T. M. Lin, C. H. Yang, and W. H. H. Sheu, "Protective effects of eugenol against oxidized LDL-induced cytotoxicity and adhesion molecule expression in endothelial cells," Food and Chemical Toxicology, vol. 44, no. 9, pp. 14851495, 2006.

[52] H. C. Ou, F. P. Chou, T. M. Lin, C. H. Yang, and W. H. H. Sheu, "Protective effects of honokiol against oxidized LDL-induced cytotoxicity and adhesion molecule expression in endothelial cells," Chemico-Biological Interactions, vol. 161, no. 1, pp. 1-13, 2006.

[53] M. Manttari, E. Tiula, T. Alikoski, and V. Manninen, "Effects of hypertension and dyslipidemia on the decline in renal function," Hypertension, vol. 26, no. 4, pp. 670-675, 1995.

[54] P. Muntner, J. Coresh, J. C. Smith, J. Eckfeldt, and M. J. Klag, "Plasma lipids and risk of developing renal dysfunction: the atherosclerosis risk in communities study," Kidney International, vol. 58, no. 1, pp. 293-301, 2000.

[55] L. F. Fried, T. J. Orchard, and B. L. Kasiske, "Effect of lipid reduction on the progression of renal disease: a meta-analysis," Kidney International, vol. 59, no. 1, pp. 260-269, 2001.

[56] A. V. Chobanian, G. L. Bakris, H. R. Black et al., "Joint National Committee on Prevention, Detection, Evaluation, and Treatment of High Blood Pressure; National Heart, Lung, and Blood Institute; National High Blood Pressure Education Program Coordinating Committee 2003 Seventh report of the Joint National Committee on Prevention, Detection, Evaluation, and Treatment of High Blood Pressure," Hypertension, vol. 42, no. 6, pp. 1206-1252, 2003.

[57] E. Ferrannini, G. Buzzigoli, R. Bonadonna et al., "Insulin resistance in essential hypertension," The New England Journal of Medicine, vol. 317, no. 6, pp. 350-357, 1987.

[58] H. O. Steinberg, G. Brechtel, A. Johnson, N. Fineberg, and A. D. Baron, "Insulin-mediated skeletal muscle vasodilation is nitric oxide dependent: a novel action of insulin to increase nitric oxide release," Journal of Clinical Investigation, vol. 94, no. 3, pp. 1172-1179, 1994.

[59] J. E. Tooke and M. M. Hannemann, "Adverse endothelial function and the insulin resistance syndrome," Journal of Internal Medicine, vol. 247, no. 4, pp. 425-431, 2000.

[60] T. Fujita, "Aldosterone in salt-sensitive hypertension and metabolic syndrome," Journal of Molecular Medicine, vol. 86, no. 6, pp. 729-734, 2008.
[61] D. Tripathy, P. Mohanty, S. Dhindsa et al., "Elevation of free fatty acids induces inflammation and impairs vascular reactivity in healthy subjects," Diabetes, vol. 52, no. 12, pp. 2882-2887, 2003.

[62] T. P. Combs, A. H. Berg, S. Obici, P. E. Scherer, and L. Rossetti, "Endogenous glucose production is inhibited by the adiposederived protein Acrp30," Journal of Clinical Investigation, vol. 108, no. 12, pp. 1875-1881, 2001.

[63] H. Xu, G. T. Barnes, Q. Yang et al., "Chronic inflammation in fat plays a crucial role in the development of obesity-related insulin resistance," Journal of Clinical Investigation, vol. 112, no. 12, pp. 1821-1830, 2003.

[64] L. Azadbakht, P. Mirmiran, A. Esmaillzadeh, T. Azizi, and F. Azizi, "Beneficial effects of a dietary approaches to stop hypertension eating plan on features of the metabolic syndrome," Diabetes Care, vol. 28, no. 12, pp. 2823-2831, 2005.

[65] S. Liu, H. K. Choi, E. Ford et al., "A prospective study of dairy intake and the risk of type 2 diabetes in women," Diabetes Care, vol. 29, no. 7, pp. 1579-1584, 2006.

[66] H. K. Choi, W. C. Willett, M. J. Stampfer, E. Rimm, and F. B. $\mathrm{Hu}$, "Dairy consumption and risk of type 2 diabetes mellitus in men: a prospective study," Archives of Internal Medicine, vol. 165, no. 9, pp. 997-1003, 2005.

[67] M. A. Pereira, D. R. Jacobs, L. Van Horn, M. L. Slattery, A. I. Kartashov, and D. S. Ludwig, "Dairy consumption, obesity, and the insulin resistance syndrome in young adults: the CARDIA study," Journal of the American Medical Association, vol. 287, no. 16, pp. 2081-2089, 2002.

[68] D. Giugliano, A. Ceriello, and K. Esposito, "Are there specific treatments for the metabolic syndrome?" The American Journal of Clinical Nutrition, vol. 87, no. 1, pp. 8-11, 2008.

[69] I. S. Hoffmann and L. X. Cubeddu, "Increased blood pressure reactivity to dietary salt in patients with the metabolic syndrome," Journal of Human Hypertension, vol. 21, no. 6, pp. 438-444, 2007.

[70] J. Chen, D. Gu, J. Huang et al., "Metabolic syndrome and salt sensitivity of blood pressure in non-diabetic people in China: a dietary intervention study," The Lancet, vol. 373, no. 9666, pp. 829-835, 2009.

[71] T. J. Orchard, M. Temprosa, R. Goldberg et al., "The effect of metformin and intensive lifestyle intervention on the metabolic syndrome: the diabetes prevention program randomized trial," Annals of Internal Medicine, vol. 142, no. 8, pp. 611-619, 2005.

[72] Diabetes Prevention Program Research Group, "10-year follow-up of diabetes incidence and weight loss in the Diabetes Prevention Program Outcomes Study," The Lancet, vol. 374, no. 9702, pp. 1677-1686, 2009.

[73] C. Vitale, G. Mercuro, A. Cornoldi, M. Fini, M. Volterrani, and G. M. C. Rosano, "Metformin improves endothelial function in patients with metabolic syndrome," Journal of Internal Medicine, vol. 258, no. 3, pp. 250-256, 2005.

[74] S. R. Salpeter, E. Greyber, G. A. Pasternak, and E. E. Salpeter, "Risk of fatal and nonfatal lactic acidosis with metformin use in type 2 diabetes mellitus: systematic review and metaanalysis," Archives of Internal Medicine, vol. 163, no. 21, pp. 2594-2602, 2003.

[75] DREAM (Diabetes Reduction Assessment with ramipril and rosiglitazone Medication) Trial Investigators, H. C. Gerstein, S. Yusuf et al., "Effect of rosiglitazone on the frequency of diabetes in patients with impaired glucose tolerance or 
impaired fasting glucose: a randomised controlled trial," The Lancet, vol. 368, no. 9541, pp. 1096-1105, 2006.

[76] P. Szapary, L. Bloedon, F. F. Samaha et al., "The effects of pioglitazone on lipoproteins in non-diabetics with metabolic syndrome: results from a randomized controlled trial," in Proceedings of the 65th Scientific Sessions of the American Diabetes Association: Program and Abstracts, San Diego, Calif, USA, June 2005.

[77] M. H. Tan, A. Deeg, and R. B. Goldberg, "Comparison of pioglitazone and rosiglitazone on atherogenic index of plasma in patients with type 2 diabetes and dyslipidemia," in Proceedings of the 65th Scientific Sessions of the American Diabetes Association: Program and Abstracts, San Diego, Calif, USA, June 2005.

[78] Expert Panel on Detection, Evaluation, and Treatment of High Blood Cholesterol in Adults, "Executive summary of the third report of the National Cholesterol Education Program (NCEP) expert panel on detection, evaluation, and treatment of high blood cholesterol in adults (adult treatment panel III)," Journal of the American Medical Association, vol. 285, no. 19, pp. 2486-2497, 2001.

[79] P. Deedwania, P. Barter, R. Carmena et al., "Reduction of lowdensity lipoprotein cholesterol in patients with coronary heart disease and metabolic syndrome: analysis of the treating to new targets study," The Lancet, vol. 368, no. 9539, pp. 919-928, 2006.

[80] C. M. Ballantyne, A. G. Olsson, T. J. Cook, M. F. Mercuri, T. R. Pedersen, and J. Kjekshus, "Influence of low high-density lipoprotein cholesterol and elevated triglyceride on coronary heart disease events and response to simvastatin therapy in 4S," Circulation, vol. 104, no. 25, pp. 3046-3051, 2001.

[81] C. M. Ballantyne, E. A. Stein, R. Paoletti et al., "Efficacy of rosuvastatin $10 \mathrm{mg}$ in patients with the metabolic syndrome," American Journal of Cardiology, vol. 91, no. 5, pp. 25-27, 2003.

[82] M. Takemoto and J. K. Liao, "Pleiotropic effects of 3hydroxy-3-methylglutaryl coenzyme A reductase inhibitors," Arteriosclerosis, Thrombosis, and Vascular Biology, vol. 21, no. 11, pp. 1712-1719, 2001.

[83] J. G. Robinson, C. M. Ballantyne, S. M. Grundy et al., "Lipidaltering efficacy and safety of ezetimibe/simvastatin versus atorvastatin in patients with hypercholesterolemia and the metabolic syndrome (from the VYMET Study)," American Journal of Cardiology, vol. 103, no. 12, pp. 1694-1702, 2009.

[84] G. Mancia, G. De Backer, A. Dominiczak et al., "2007 guidelines for the management of arterial hypertension: the task force for the management of arterial hypertension of the European Society of Hypertension (ESH) and of the European Society of Cardiology (ESC)," Journal of Hypertension, vol. 25, no. 6, pp. 1105-1187, 2007.

[85] W. J. Elliott and P. M. Meyer, "Incident diabetes in clinical trials of antihypertensive drugs: a network meta-analysis," The Lancet, vol. 369, no. 9557, pp. 201-207, 2007.

[86] F. H. Messerli, E. Grossman, and G. Leonetti, "Antihypertensive therapy and new onset diabetes," Journal of Hypertension, vol. 22, no. 10, pp. 1845-1847, 2004.

[87] J. T. Wright, S. Harris-Haywood, S. Pressel et al., "Clinical outcomes by race in hypertensive patients with and without the metabolic syndrome: Antihypertensive and Lipid-Lowering Treatment to Prevent Heart Attack Trial (ALLHAT)," Archives of Internal Medicine, vol. 168, no. 2, pp. 207-217, 2008.

[88] H. R. Black, B. Davis, J. Barzilay et al., "Metabolic and clinical outcomes in nondiabetic individuals with the metabolic syndrome assigned to chlorthalidone, amlodipine, or lisinopril as initial treatment for hypertension: a report from the
Antihypertensive and Lipid-Lowering Treatment to Prevent Heart Attack Trial (ALLHAT)," Diabetes Care, vol. 31, no. 2, pp. 353-360, 2008.

[89] B. Strasser, U. Siebert, and W. Schobersberger, "Resistance training in the treatment of the metabolic syndrome: a systematic review and meta-analysis of the effect of resistance training on metabolic clustering in patients with abnormal glucose metabolism," Sports Medicine, vol. 40, no. 5, pp. 397415,2010 .

[90] W. J. Lee, M. T. Huang, W. Wang, C. M. Lin, T. C. Chen, and I. R. Lai, "Effects of obesity surgery on the metabolic syndrome," Archives of Surgery, vol. 139, no. 10, pp. 1088-1092, 2004. 


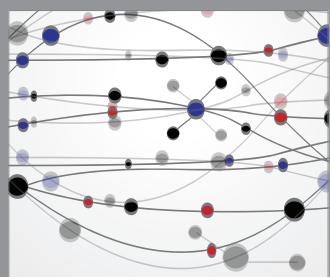

The Scientific World Journal
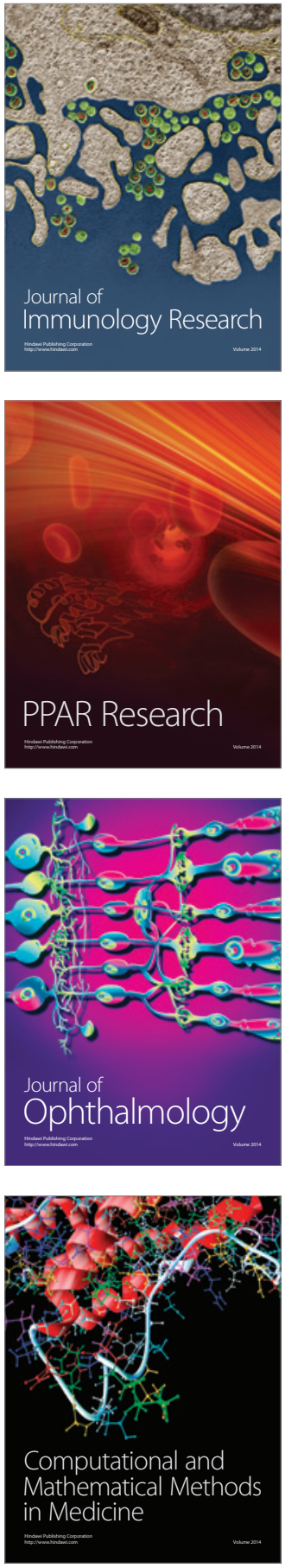

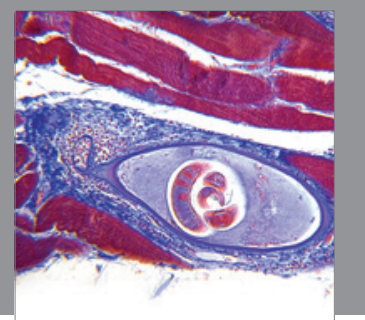

Gastroenterology

Research and Practice
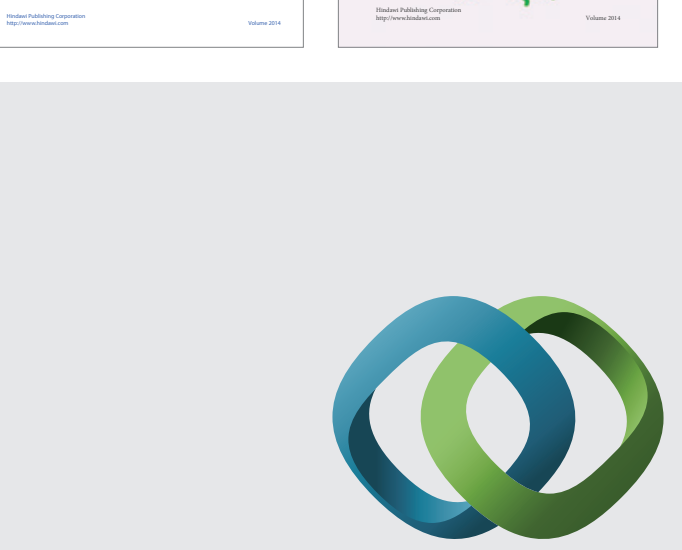

\section{Hindawi}

Submit your manuscripts at

http://www.hindawi.com
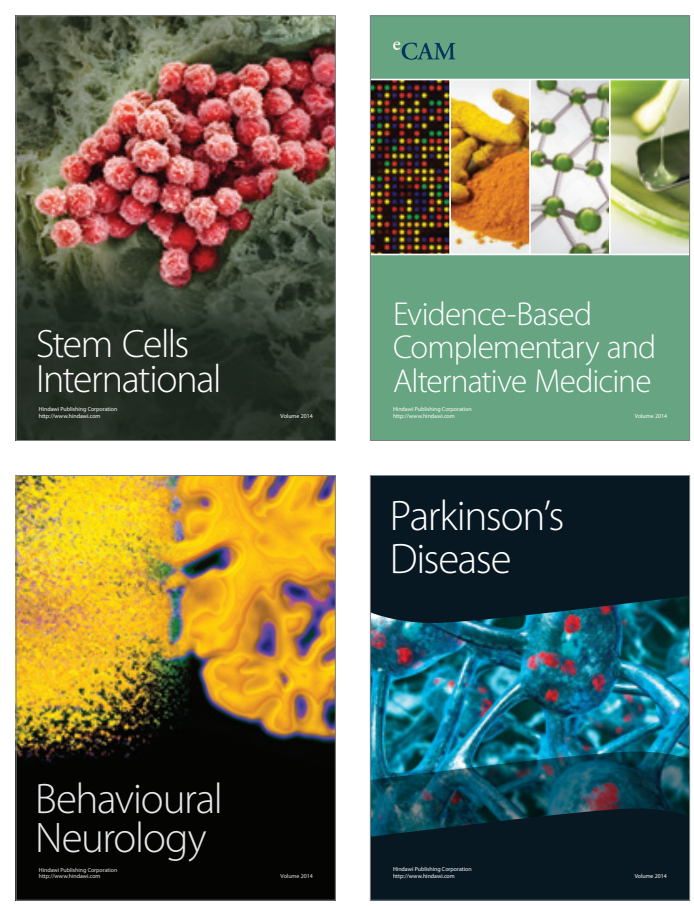

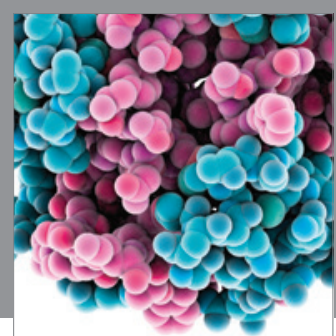

Journal of
Diabetes Research

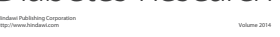

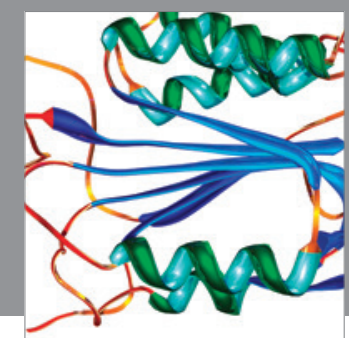

Disease Markers
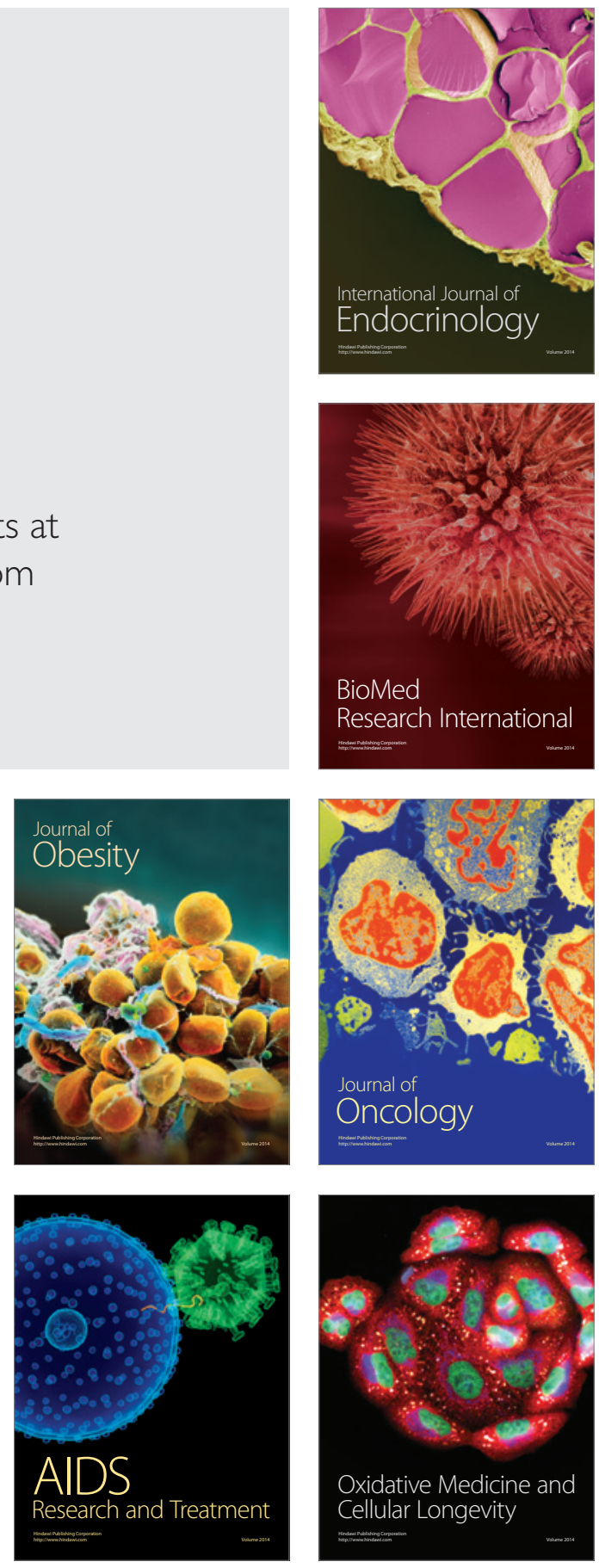